\title{
A MID-BRAIN SYNDROME FOLLOWING HEAD INJURY
}

\author{
BY \\ MICHAEL KREMER, W. RITCHIE RUSSELL, and G. E. SMYTH \\ (ReCEIVED 6TH DeCEMBER, 1946)
}

HAMORRHAGIC lesions of the brain stem are not infrequently found in fatal cases of accidental head injury. Duret $(1878,1919)$ emphasized their importance, and showed that they are easily produced in experimental animals. Berner (1930) and Courville (1945) also considered them to be an important cause of death, and it is clear that only a very few patients who recover from a head injury are found to have the clinical signs of severe brainstem injury. Transient signs of brain-stem injury are, however, not uncommon, and may consist of pupillary and oculo-motor abnormalities or even decerebrate rigidity, while Denny-Brown (1941) has described cases showing delayed collapse after head injury with clinical features indicating bulbar involvement.

A few severe cases of mid-brain injury have previously been reported, one of the most striking being by Sachs (1930). The purpose of this paper is to draw attention to a rare type of case in which there is severe and permanent motor disability, probably caused by damage to the mid-brain. Air encephalography carried out in two of the cases showed dilatation of the aqueduct of Sylvius. The nine cases here described were patients in the Military Hospital for Head Injuries, Oxford, and represented a proportion of about one in 700 of the cases of accidental head injury admitted.

\section{Case Reports}

Case 1.-A driver, aged 34, met with a road accident on Aug. 24, 1944. Two and a half hours later he was unconscious, with constricted pupils, spasticity of all limbs, extensor plantar responses, and trismus. The pulse was 92 per minute, respiration 20 per minute, the blood pressure $128 / 76 \mathrm{~mm}$. $\mathrm{Hg}$. On the following morning ( 9 hours after the injury) the temperature rose to $105 \cdot 2^{\circ} \mathrm{F}$., but fell to $102^{\circ} \mathrm{F}$. some hours later. Spasticity had by now become more marked. Radiographs of the skull did not disclose any evidence of fracture. On the second day a "tonic fit" occurred, affecting the right arm and leg, but no further details are available. During the next twelve days he was very restless, "thrashed about with his legs whenever disturbed," and ran a constant temperature at about $102^{\circ} \mathrm{F}$, which once reached $105 \cdot 6^{\circ} \mathrm{F}$. Thereafter the fever subsided. From Sept. 18 the stupor lessened and the patient began to swallow soft food. At times he had fits of choking. Spasticity diminished but the plantar responses remained extensor. All voluntary movements were noted as "very jerky." By now he would obey simple commands, but he made no attempt to speak. Frequent and severe sweats were noticed, which appeared to cause great irritation of the skin, for he would rub and scratch himself with such violence that restraint was necessary. On examination on Oct. 17, 1944, it was found that the patient's general condition was fair. He was restless and speechless.

Cranial Nerves.--Visual acuity was not measured but he could certainly see. Visual fields and fundi were normal. The right pupil was $5 \mathrm{~mm}$. in diameter, the left $4 \mathrm{~mm}$., both being circular and reacting promptly to light but through a small range. External ocular movements were full, with no nystagmus. There was slight right ptosis. Cranial nerves were otherwise normal, but there was considerable dysphagia.

Motor Functions.-There was slight spastic weakness of the right arm and leg. Tendon reflexes were all increased, more particularly on the right, and both plantar reflexes were extensor. Abdominal reflexes were present. The cerebrospinal fluid was clear, under a pressure of $140 \mathrm{~mm}$. of water, and contained $45 \mathrm{mg}$. per cent. of protein and 6 cells per c.mm. An electroencephalogram showed the presence of generalized medium-voltage slow waves, but no evidence of a focal lesion. The patient remained speechless, incontinent and, at times, violent until the middle of November.

By Dec. 1 the mental state had improved considerably. Speech had returned, but was so dysarthric as to be almost unintelligible. The voice was produced with great effort. The tone was high-pitched, monotonous, and curiously hissing in quality. Words were slurred and scanned, but vowels were even more distorted than consonants. The expression was fixed and fatuous, and the mood appeared happy and childish. He took little interest in his surroundings, and was poorly in touch with current events. Information obtained from his wife showed that previously he had been a highly intelligent and successful business man of stable and cheerful disposition. The photographs in Fig. 2 (see p. 54-5) were extracted from a cinematograph film and give some idea of the motor disorder and loss of balance. He 
adopted, when sitting, a fixed bodily posture, with the head and trunk bent slightly forward. There were irregular and inconstant fidgety movements of the limbs. He was unable to stand unaided, and attempts at walking, when supported by two persons, led to wild movements of the trunk and lower limbs, without any control of their direction or extent. There was occasional nodding tremor of the head, and frequent outbursts of rhythmic alternating flexion and extension of the right thumb and index finger at about two and a half alternations a second. At times this tremor siffed to the right ring and little finger, leaving the thumb and index at rest.

Cranial Nerves.-There was bilateral lid retraction; with slight internal strabismus. The pupils were semidilated, the right larger than the left, and a little irregular in outline. Reaction to light was brisk through a small range, and there was minimal contraction on convergence. External ocular movements were full, with no nystagmus. There was bilateral facial rigidity, with constant blepharoclonus on closing the eyes. Jaw jerk was not increased.

Motor Functions.-There was no wasting. Tone was slightly increased on the right, particularly in the arm ; it was of pyramidal rather than of striatal type, with no real loss of power. There was an extreme degree of ataxia of all limbs, but more on the right and more marked in the arms than in the legs. He was totally unable to execute alternating movements. The tendon jerks were markedly increased, except that the right ankle jerk was difficult to obtain, and the increase in the tendon jerks was slightly more marked on the left side than on the right. The abdominal reflexes were present. The plantar responses were both extensor. The condition remained unchanged till his transfer to another hospital on June 8, 1945. On April 14, 1945 (eight months after the injury), lumbar air-encephalography was performed. This showed a moderate dilatation of lateral ventricles but without any distortion or displacement. The aqueduct of Sylvius was considerably dilated (Fig. 1) and the fourth ventricle slightly so. The cisterna magna was enlarged, and air could be seen filling the cistern from the foramen magnun to as high as the curved line of the occipital bone. In November, 1946, his wife reported he was still unable to walk or to use his hands properly.

SuMMARY OF FINDINGS.-There was severe closed head injury with post-traumatic confusion of some three months' duration. Fever, rising on two occasions to $105^{\circ} \mathrm{F}$., occurred in the first few weeks. Initially there was marked spasticity of all the limbs. The patient was anarthric and dysphagic for two months ; speech returned thereafter, but was grossly dysarthric. As the spasticity lessened, an intense ataxia of all the limbs and the trunk became evident, and rhythmic coarse tremor of the right hand and fingers developed. The tendon jerks were pathologically brisk, and the plantar responses extensor. There was a moderate degree of dementia. Air encephalography showed marked dilatation of the aqueduct of Sylvius, and some increase in the size of the cisterna magna.

Case 2.-A sapper, aged 19, sustained a severe closed head injury with laceration of the scalp and fractures of both legs when a rocket bomb hit his billet on or about Dec. 16, 1944. The early notes record that he was unconscious, with small pupils, and that there was no spasticity. No early note on the temperature exists, but some days later it was normal. The pulse rate was 100 to 120 per minute, and the blood pressure $180 / 110$ $\mathrm{mm}$. $\mathrm{Hg}$, but within a week both had fallen to normal levels. He was evacuated to England on Jan. 6, 1945. On examination on Jan. 6 he was found to be considerably emaciated and very inaccessible, owing to an almost total anarthria. Apparent attempts at speech produced only a harsh long-drawn-out hissing sound. Simple commands were obeyed fairly well.

Cranial Nerves. - Visual fields appeared full. At rest the right eye deviated downwards and outwards, whilst the left remained central. The right pupil was larger than the left; both reacted to light. The external ocular movements were very defective, for there was no upward or inward movement of the right globe and none upward or outward of the left. The defective lateral conjugate movements were accompanied by rather coarse nystagmus.

Motor Functions.-The left arm was hypotonic, and the patient made no attempt to use it voluntarily. The left leg was raised with difficulty (both legs were in plaster casts). All accessible tendon jerks were brisk, the abdominal responses were present, and the plantaro responses flexor. Sensibility seemed intact. The cerebrospinal fluid was under normal pressure, and the celfo content and chemical analyses were normal. Radio-? graphs of the skull showed a slight widening of the left lambdoid suture but no sign of fracture.

Progress.-On Jan. 12, 1945, he was still restless and severely confused. Speech was now comprehensib.e, but the prolonged and harsh hissing quality of expiration persisted. Vowel sounds were much more perverted than were consonants. The peculiar character of the speech recalled the bleat of a sheep. The range of ocular movements had increased, but neither eye adducted fully. There was no convincing nystagmus, but some slow oscillations were seen on extreme lateral movement. By the beginning of March he was able to be up for most of the day. The post-traumatic amnesia was of some ten weeks' duration. His behaviour in the ward was normal. There was little evidence of intellectual deterioration, but the mood was somewhat depressed. He complained of double vision, and of uselessness of the left arm and leg. He thought his speech was normal, but that the voice lacked power. A slight bilateral ptosis, more marked on the right side, was noticeable.

Examination on May 1, 1945, showed the general condition greatly improved. A complete psychiatric examination failed to show any evidence of intellectual loss or personality change. He got about the ward well, but the left leg was.weak and unsteady and the left arm 
so weak and clumsy as to be almost useless. The voice was weak and low pitched, and a trace of scanning dysarthria was detectable. He himself said that, whereas formerly he could sing quite well, now the voice did not come out properly: "I can't manage the breathing, Sir."

Cranial Nerves.-There was an intermittent slight nodding tremor of the head at two to three oscillations a second. Slight bilateral ptosis was present as at the last examination. Pupils were equal, and reacted normally to light. Convergence was poor, and only minimal pupillary contraction occurred. External ocular movements were full, except for limitation of adduction of the left eye. Testing by means of a Hess diplopia chart showed a paresis of mixed type, i.e. affecting the right superior rectus and inferior oblique muscles and the left inferior and internal recti and superior oblique muscles, and almost certainly indicative of a nuclear lesion. An ill-sustained and inconstant nystagmus occurred on lateral and upward movement of the eyes. In involuntary and associated movement the left lower face drooped a little. The right facial nerve showed hyperexcitability on tapping the trunk just anterior to the tragus.

Motor Functions.- The left arm was hypotonic and could be displaced with undue ease, but there was little or no loss of power. When the forearm and hand were not fully supported, bursts of rapid rhythmic tremor occurred in the left index and middle fingers at a rate of three or four beats a second. This tremor was a simple movement of flexion and extension. There was gross kinetic ataxia in the finger-nose test, with well-marked terminal accentuation. Individual finger movements were very slow and laboured, while alternating movements could not be executed at all. The left leg was much less hypotonic than the arm. There was no loss of power. In the heel-shin test a very coarse and irregular ataxia was evident. Wriggling of the left toes was, however, only slightly slower than on the right. There was no disturbance of motor functions in the right limbs. The gait was slightly unsteady, but with no tendency to veer to one side more than the other. The tendon reflexes were in general increased on the left side, and the abdominal reflexes were present and equal. The plantar responses were at all times difficult to assess, and varied from day to day. Both were probably pathological. There was no disturbance of sensibility. Lumbar encephalography (May 9, 1945) showed complete absence of dilatation of the lateral and third ventricles. There was an excess of air over the occipital poles. The striking abnormality was the very considerable dilatation of the aqueduct of Sylvius (Fig. 3).

SUMMARY OF FINDINGS.- - This patient had a closed head injury with post-traumatic amnesia of about ten weeks. Initially there was anarthria; later a curious harsh hissing type of phonation. Finally there was only a slight scanning dysarthria, and severe and lasting hypotonia of the left limbs, with gross ataxia and inability to execute discrete and alternating movement. There was an intermittent
Parkinsonian-like tremor of the fingers of the left hand. Tendon reflexes were more active on the left than the right. There was enduring diplopia from what was considered to be a nuclear ophthalmoplegia. Dilatation of the aqueduct of Sylvius was demonstrated by air encephalography.

Case 3.-A Flight-Sergeant, aged 21, was injured in an air crash on Nov. 27, 1943. He was at first deeply comatose, and there was a post-traumatic amnesia of seventeen days. Radiographs showed that he had sustained a fissured fracture of the left parietal bone. Operation was carried out, and depressed bone fragments removed. The dura had not been perforated. On regaining consciousness there was thick, indistinct speech, some disturbance of vision, and inability to control movements of the left arm and leg. The notes stated that when the left arm was held outstretched it developed a coarse clonus. On examination (Jan. 18, 1944) he was found to be fully alert and in touch with his surroundings. He was, however, markedly euphoric and disinhibited. Speech was noted as being of the kind associated with cerebellar disease.

Cranial Nerves.-Pupillary reactions were normal. External ocular movements were full, but on extreme lateral movement a fine nystagmus appeared. There was slight but definite left ptosis.

Motor Functions.-All limbs were hypotonic, but the left side was the more affected. There was minimal weakness of the left leg only. Alternating movements were performed very slowly and clumsily with the left hand, rather better in the right hand and in both feet. Individual finger movements were very poor on the left, and slightly impaired on the right. There was marked ataxia in all limbs, particularly so on the left side. The gait was reeling, and constantly deviated towards the right. The tendon jerks were all more brisk on the left, and the left plantar response was less frankly flexor than' the right. The abdominal reflexes were present and equal. Sensibility was unimpaired.

Progress.-Whilst at a convalescent hospital he had an attack of pain in the right side of the face, and it was thought that there was a slight depression to pinprick over the right trigeminal area. The corneal reflexes were, however, not impaired. An electro-encephalogram on March 6, 1944, was normal. Air encephalography was not carried out. In November, 1946, he still complained of difficulty in balance and weakness of the left arm and leg.

SumMARY OF FINDINGS.-This patient had a severe closed head injury followed by dysarthria of "cerebellar" type, hypotonia and ataxia of the limbs, particularly on the left side, and slight personality change.

Case 4.-A trooper, aged 19, was injured in a motor cycle accident on July 3, 1941. There was stupor for three days, and a post-traumatic amnesia of three weeks. No fracture was seen in radiographs of the skull. On regaining consciousness it was reported that speech was very dysarthric. On examination on Aug. 11, 1941, he 
was alert and co-operative and showed no signs of intellectual impairment. Slurring dysarthria was very evident, speech being thick and lacking in definition.

Crantal Nerves.-The right pupil was larger than the left and reacted less well to light. When he looked downwards there was diplopia from paresis of the right superior oblique muscle. The external ocular movements were otherwise full, and there was no nystagmus. The right lower face moved less than the left in emotional and associated movements.

MOTOR Functions.-There was probably some hypotonia of the right hand, but no weakness or ataxia. Individual and alternating movements of the fingers were not so well performed on the right as on the left, and toe wriggling was slower on the right than on the left. His gait was a little unsteady, and he was prone to veer towards the right. The tendon jerks and abdominal reflexes were all present and equal, and both plantar responses were flexor in type.

Progress.-The signs persisted unchanged, and he was invalided from the Service on Feb. 11, 1942. When re-examined a year later he still had diplopia and dysarthria. The facial weakness had cleared up. He was reading for a degree at a University.

Summary OF Findings.-A severe closed head injury showed, as recovery occurred, dysarthria, diplopia from paresis of the right superior oblique muscle, and hypotonia of the right hand. The dysarthria and diplopia were still present eighteen months after the injury.

Case 5.-A rifleman, aged 21, was crushed between a lorry and a steel girder on Dec. 6, 1941. He had a post-traumatic amnesia of only about six hours. Radiographs showed a comminuted fracture in the anterior part of the left parietal bone. He stated that for several days after regaining consciousness he was totally unable to make any comprehensible sounds although knowing quite well the words he wished to utter. It was two weeks before he was able to make himself understood. He was able to grasp firmly, but the hands were so unsteady that he was quite unable to carry food to his mouth. On examination on Dec. 23 he was found to be alert, cheerful and rather euphoric, but with no other evidence of personality change or intellectual impairment. Dysarthria was the most striking feature, and he was very difficult to understand. The speech was slow, the tone monotonous, and the words broken up into separate syllables.

Crantal Nerves.-The pupils were dilated and eccentric but equal in size. The reactions to light and convergence were normal. A slight but well sustained nystagmus was present. There was neither squint nor diplopia. There was a slight left lower facial weakness, best seen in emotional and associated movements.

MOTOR Functions.-Tone was generally diminished in all limbs, and the right hand grasp was less strong than the left. There was a slight ataxia with terminal accentuation in both upper limbs, but more on the right than on the left. In the lower limbs a slight degree of ataxia was noted in the left leg only. Alternating movements of the hands and individual movements of the fingers were impaired on both sides, but the right side was the more severely affected. The tendon jerks were all present and equal. The plantar responses were variable ; on one occasion only were they frankly extensor. The gait was slightly ataxic.

Progress.-An unexplained attack of fever of $103^{\circ} \mathrm{F}$. lasting about two days occurred on Dec. 15, 1941. The cerebrospinal fluid was normal. Electro-encephalography on Feb. 2 1942, was normal except that the dominant frequency was seven a second.

When re-examined on Jan. 15, 1947, he had just failed in an examination for Chartered Accountancy because he could not write fast enough. His right hand was still so unsteady that he had to write with his left hand, but even this was slow. In addition to a moderate ataxia of the right upper limb there was at times a rhythmical Parkinsonian-like movement of the fingers, a tremor in which the fingers flexed with a coarse rhythm. There were other abnormal movements of the right hand of an athetotic type ; for example, while writing with his left hand, the right forefinger would become hyperextended and pointing upwards from his desk in a peculiar posture which others remarked on. His speech was still ataxic, but his mental powers were well preserved.

SUMmary OF FINDINGS. - This patient had crush injury of the head with a post-traumatic amnesia of six hours. He was subsequently anarthric for several days, and thereafter was severely dysarthricog Slight generalized hypotonia was present, together with some ataxia and loss of discrete digit move-? ments. The gait was slightly ataxic. Both the right hand and speech were still severely affected five years after the injury.

Case 6.-A Flight-Sergeant, aged 21, sustained a closed head injury when his plane crashed on April 19, 1943. He was suspected of having a subdural hæmatoma, and four burr holes were made with completely negative findings. Further details of his condition in the early stage are lacking. There was a post-traumatic amnesia of about six weeks. On regaining consciousness he complained of inability to use any of his limbs, although they were in no way paralysed and could be moved freely. The right half of the face was immobile. There was constant diplopia and complete speechlessness. After a month the anarthria began to diminish. He himself described how he " gained one syllable a month" and how by January, 1944, he was able to "get out eight or nine words with one breath." Six weeks after the return of consciousness (in July, 1943) the right hand began to tremble as it lay on the bed. He did not think that movement of the arm increased this tremor. The tremor grew steadily worse, and in October the right leg and the head began to shake. By December the tremor was so violent that it shook his body. He was unable to control the tremor by an effort of will. It stopped during sleep. 


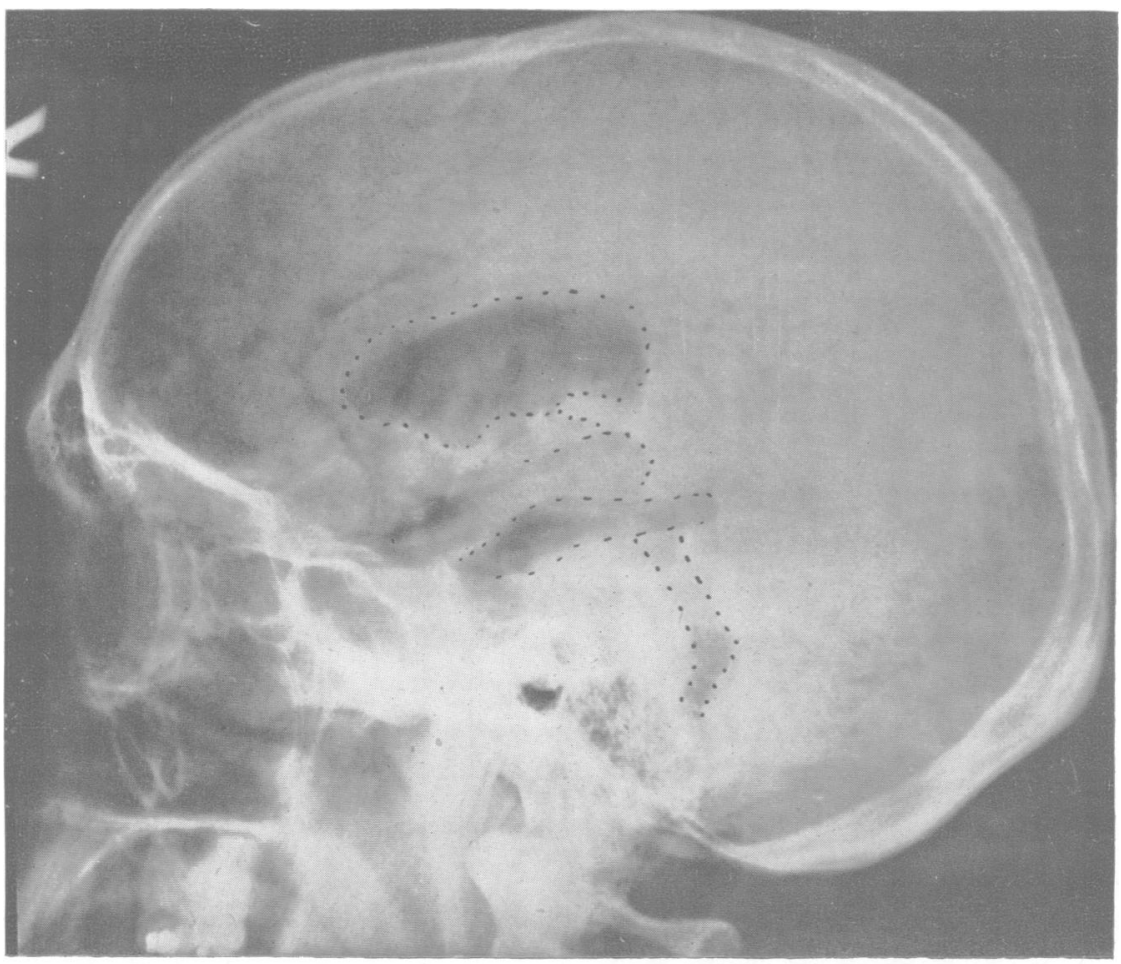

Fig. 1.-Air encephalograms in Case 1, to show dilated aqueduct. The air outline has been clarified by the dotted line. There is also a considerable quantity of air in the posterior fossa and over the occipital lobe :

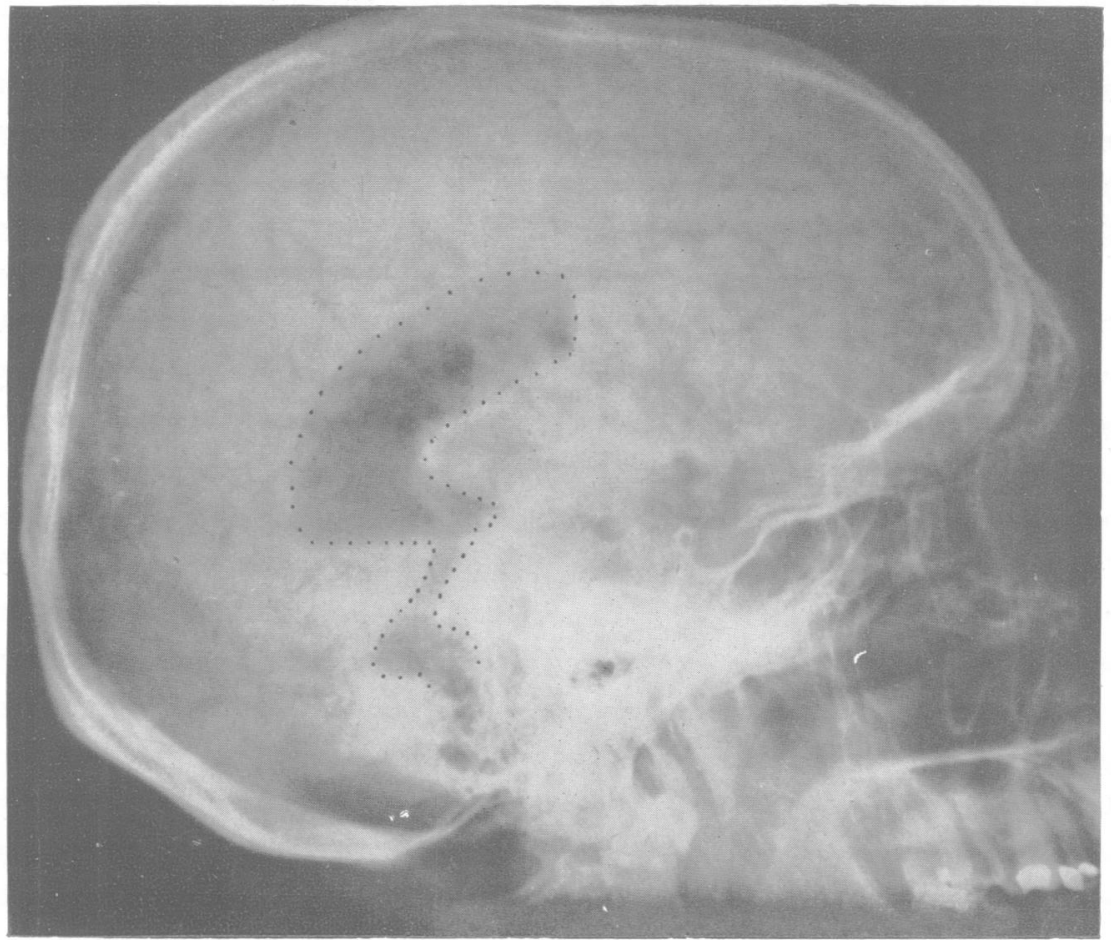

(a) brow up ;

(b) brow down. 

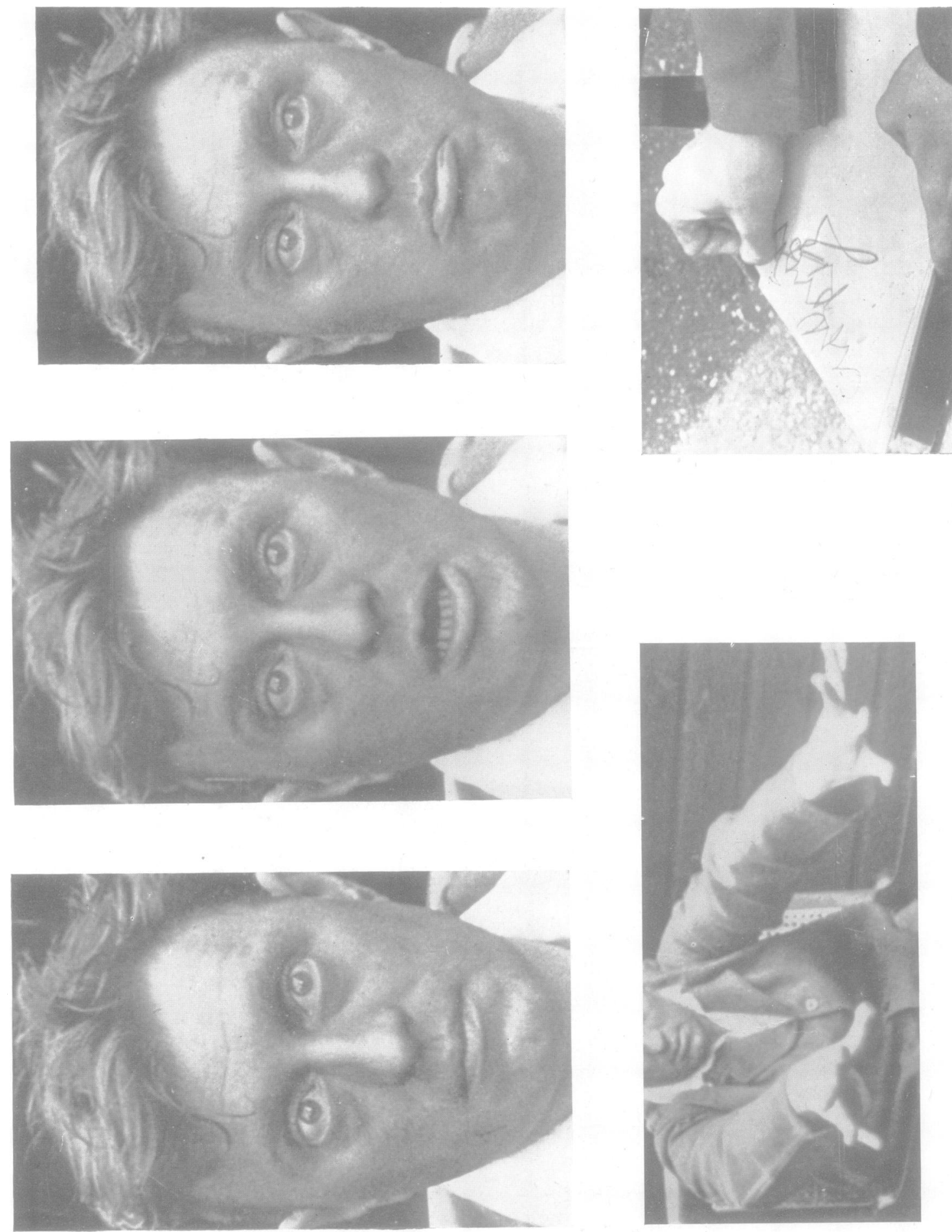

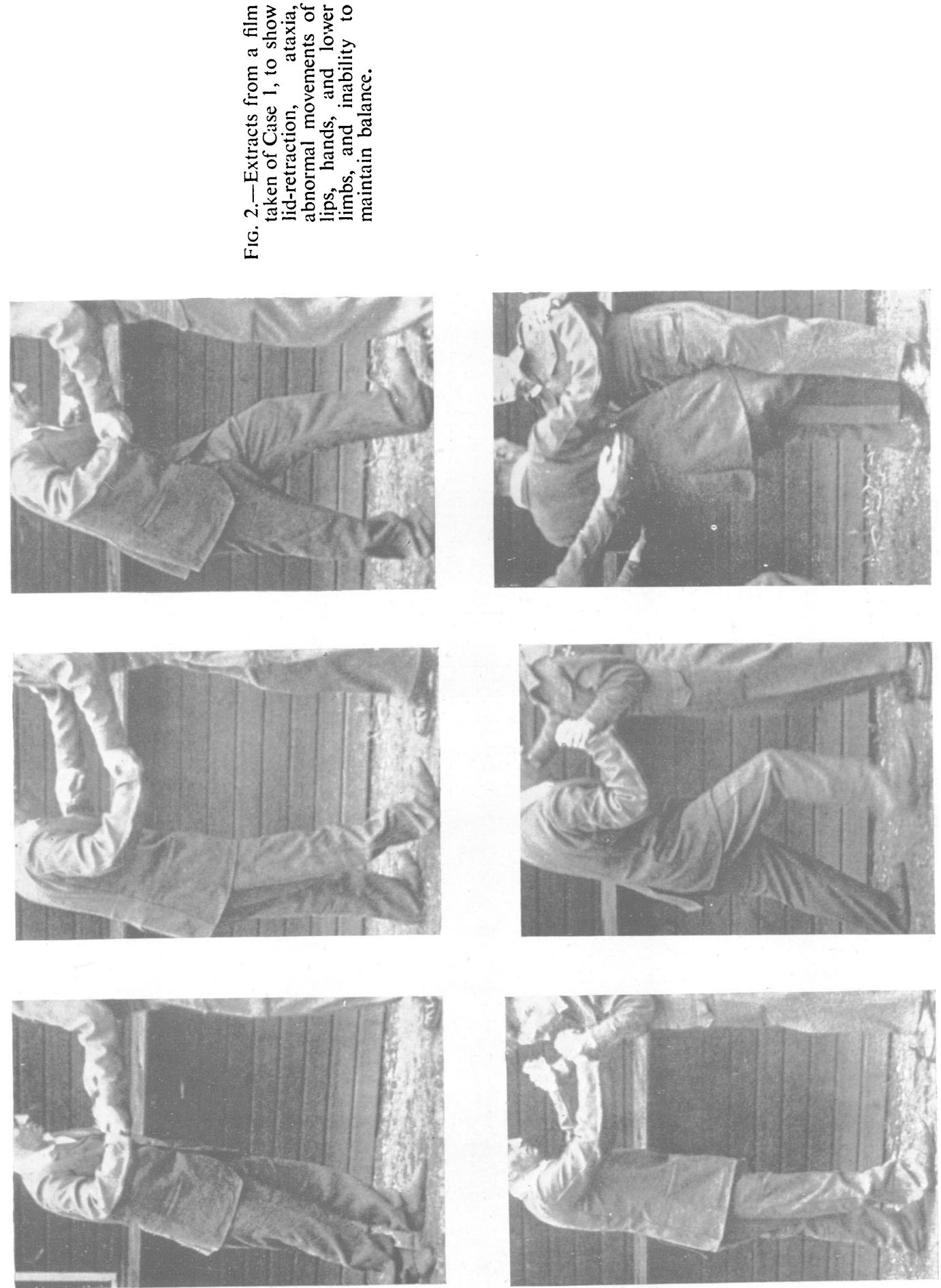


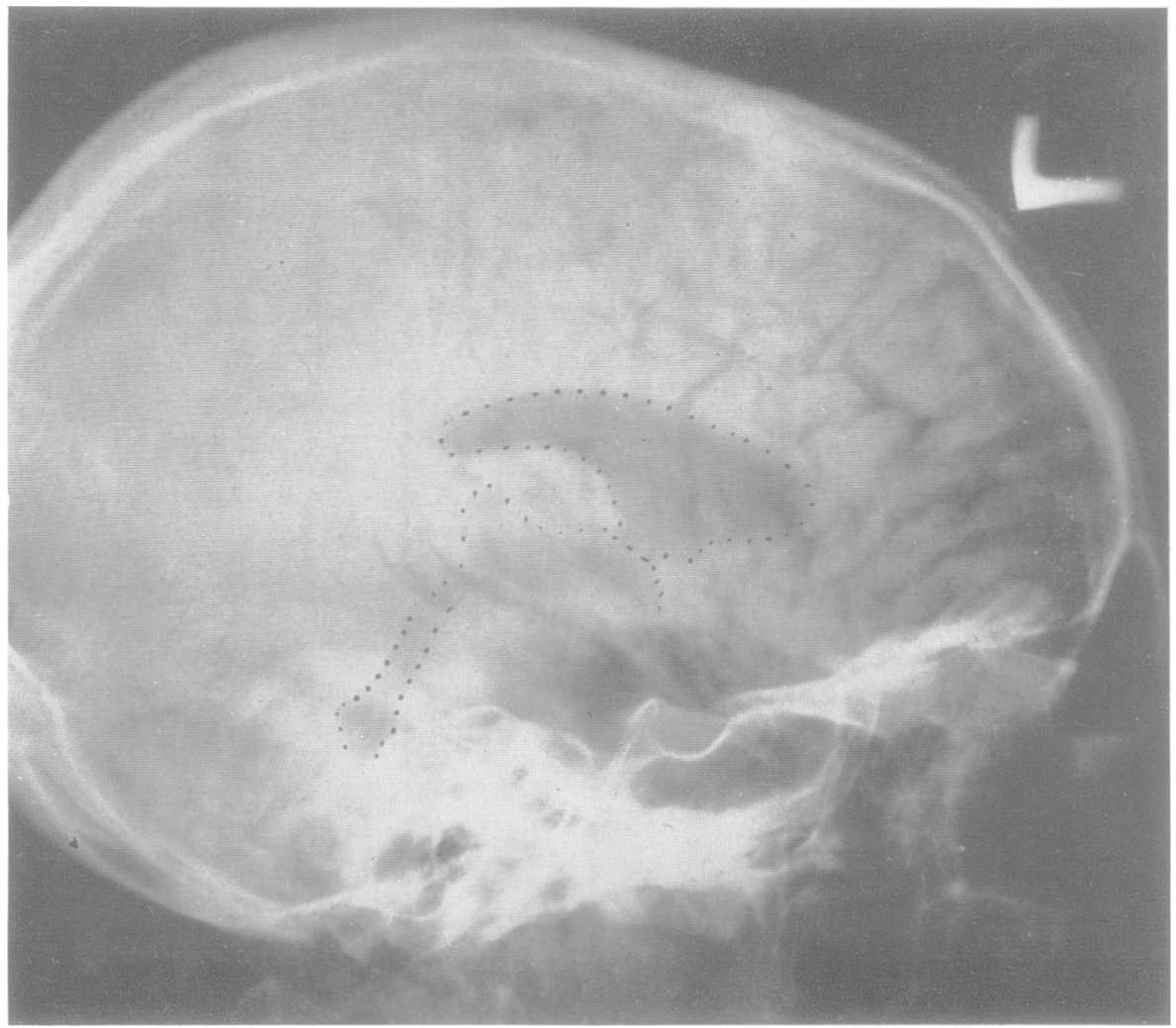

Fig. 3.-Air encephalo $\frac{\AA}{0}$ gram in Case 2, tos show dilatation of the aqueduct. The air outline has been clarified by w dotted line.

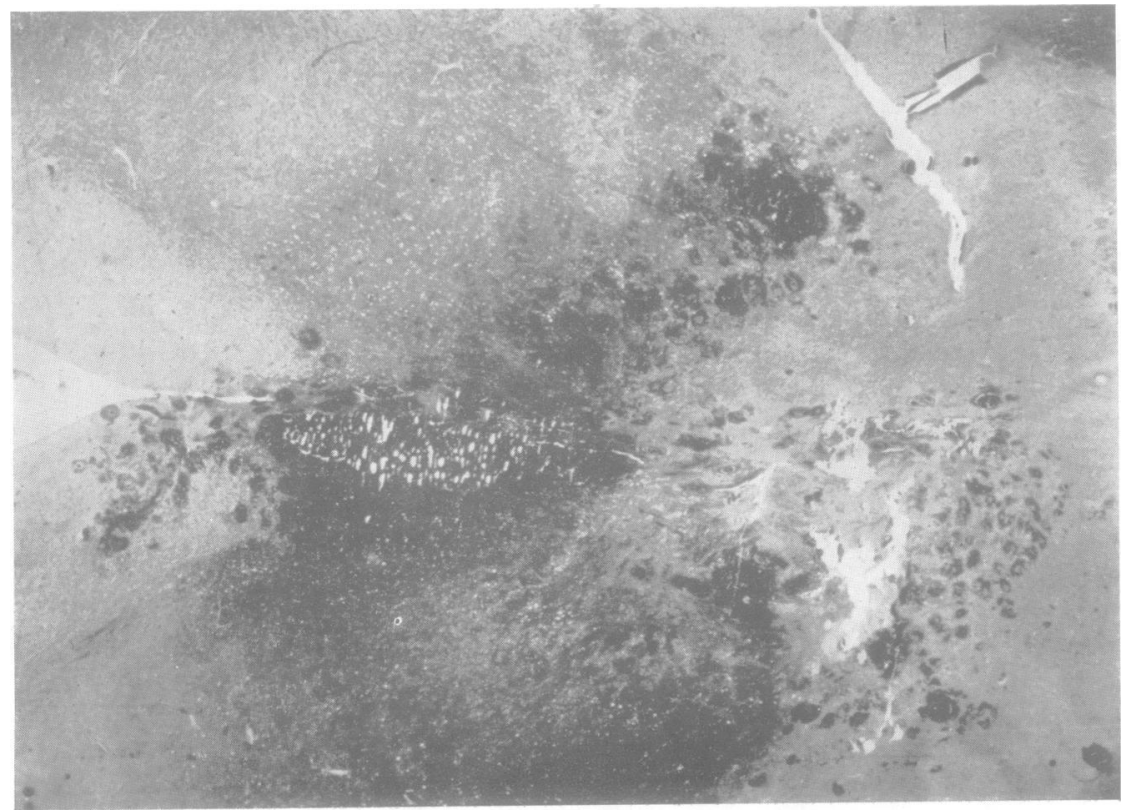

FIG. 4.-Section of the mid-brain in a case of severe head injur which survived fọ two days. The pos: terior extremity of the third ventricle is seew at the left of the seco tion, with extensive hæmorrhages betweem and within the reథ nuclei. 
On examination on Jan. 10,1944, he was found to be euphoric but there was no evidence of intellectual impairment. Memory and grasp of current events were normal. There was severe dysarthria; his speech was slow, monotonous, and somewhat slurred.

Cranial Nerves. - The right pupil was slightly larger than the left but both reacted normally to light and on convergence. There was widening of the right palpebral fissure. There was inward deviation of the right eye and slight limitation of elevation. Nystagmus was absent. Slight weakness of the right lower face and a slight and doubtful deviation of the tongue to the right were noted, but otherwise the remaining cranial nerves were normal.

MOTOR Functions.-The right arm was the seat of a marked tremor affecting all segments. In the lower extremities the right leg showed a similar tremor but less severely so, and only the proximal part of the limb was affected. The rate was about four oscillations a second. There was a slight nodding tremor of the head, which was accentuated when he turned the head towards the right side. Tone was slightly increased in the right arm and leg, while the left limbs seemed hypotonic. Power was very slightly reduced on the right side, and voluntary movements were interrupted by a jerky and irregular ataxia, which was not, however, exaggerated terminally. He was totally unable to walk, or even to hold himself erect without support. All the tendon jerks were pathologically increased. The plantar responses were flexor. Sensory functions were normal for pinprick, light touch, and vibration, but postural sense and twopoint discrimination were grossly defective in the right hand and foot.

Progress.-His condition remained unchanged during his stay in hospital. Electro-encephalography gave entirely normal results. A diagnosis of traumatic lesion of the mid-brain was made, and invaliding from the Services was advised. In November, 1946, his mother wrote to say that shakiness still prevented him from walking or writing, and that the eyes were still “ crossed."

SUMmaRY OF FINDINGS.--This patient had a severe closed head injury with long post-traumatic amnesia. One year later there was still severe dysarthria, coarse static tremors of the head and right limbs, diplopia, sensory loss and questionable pyramidal signs on the right side, and inability to walk or even stand.

Case 7.-A marine, aged 23, fell off his cycle on May 14, 1943. He was unconscious for a few hours at most, but there was a post-traumatic amnesia of two weeks. Burr holes were made on suspicion of a subdural hæmatoma, but nothing abnormal was found. The notes stated that there was initially a left hemiplegia, but this must have been of very brief duration for on June 20 , 1943 , it was noted that there was only some incoordination of the right leg and defective two-point discrimination on the right hand and on both feet. When examined on July 7,1943 , he complained of slight headache and of unsteadiness of the right hand. Slight dysarthria was present. He was euphoric, and memory was defective.

Cranial Nerves.-The pupils were equal, but the left reacted poorly to light. The reactions on convergence were good and equal. The external ocular movements were full and without nystagmus. There was slight hypalgesia in the territory of the left infra-orbital nerve.

Motor Functions.-There was no weakness. Posture was well maintained, but the right arm and leg were slightly hypotonic. There was slight ataxia in the finger-nose test on the right, and definite slowing in the pronation-supination test, and, most marked of all, in hand patting. There was a similar defect in the left arm and leg, but it was slight and insufficient to be a cause of disability to the patient. All the tendon jerks were abnormally brisk, but more so on the left side than on the right. The abdominal reflexes were diminished on the left. Both plantar responses were flexor. His gait was only slightly unsteady. There was no disturbance of sensation.

Progress.-An air encephalogram showed ventricles of normal size. As his condition showed no tendency to improve, he was invalided from the services in October, 1943.

SUMmaRY of FINDINGS.-This patient had a closed head injury with post-traumatic amnesia of two weeks' duration. He had dysarthria and slight pupillary inequality. Ataxia of the right limbs (and slightly so of the left), and slight intellectual and personality deterioration were still present six months after the injury.

Case 8.-A Pilot Officer, aged 26, who was injured in a plane crash on April 12, 1942, had post-traumatic amnesia for two to three weeks. No information of the early condition was obtainable except that the reflexes were all present and the pupils equal.

When examined on April 29 he was still slightly confused. His voice was weak, and his speech dysarthric. The pupils were equal, and the reactions normal. There was diplopia from paresis of the left superior oblique muscle. There was no nystagmus. Apart from a slight left lower facial weakness the remaining cranial nerves were ńormal.

MOTOR Functions.-There was, at most, questionable weakness of the right hand. The outstretched right arm drooped, and the hand tended to hyperpronate. The tone in the right arm was diminished, and there was moderate ataxia in the finger-nose test. Pronationsupination was much slower and more clumsy with the right arm than with the left. There was only a very slight ataxia of the right leg. The tendon jerks and abdominal reflexes were all present and equal, and the plantar responses flexor. There was no disturbance of sensation.

Progress.-During the four months he remained in hospital most of the signs regressed, but on his discharge on Sept. 4, 1942, he still showed slight ataxia in the right 
arm, and the diplopia and left lower facial weakness were still present.

SUMMARY OF FINDINGs.-This patient had severe closed head injury with subsequent dysarthria, diplopia from palsy of the left superiot oblique, left lower facial weakness, and slight ataxia of the right arm and leg.

Case 9.-A Warrant Officer, aged 27, had two flying accidents. After the first, on July 7, 1941, he had posttraumatic amnesia for ten days, and after the second, on July 1, 1942, of some five minutes. Between the accidents he continued to fly but felt his " nerve" had gone, and hated flying. After the second crash his disinclination to fly increased and he became depressed. When examined on Sept. 5, 1942, his principal complaints were headache, depression, slurred speech, and trembling of the right hand. He was markedly dysarthric. The pupils were equal, but irregular in outline. The reaction to light was poor, but quite good on convergence. There was a slight irregular nystagmus on full lateral movement. The left lower face moved less than the right.

MOTOR FúnCTIONS.-Power was well maintained. There was a slight increase of tone in the right arm, with a minimal degree of ataxia in the finger-nose test, and much more slowness of discrete and alternating movements in the hand and fingers. The tendon jerks were. increased on the right. The abdominal reflexes were present and equal, and both plantar responses were flexor. There was no alteration of sensibility.

Progress.-No significant change occurred, and he was discharged on Sept. 29, 1942 . Radiographs of the skull were normal.

SumMary of FINDINGS.-This patient had fairly severe closed head injury with a second and much slighter head injury a year later. After the second injury he was found to be depressed and irritable. Organic brain damage was shown by the dysarthria, ataxia, and clumsiness of movements of the right arm, and by the increased tendon jerks on the right side.

\section{Summary of Clinical Signs}

The cases in the present series, although differing considerably from one another in minor detail and in severity, have a strong resemblance to each other.

Speech Disorders.-Dysarthria was a prominent feature of every case and, with the exception of Case 7, was severe. In four patients the early histories showed that there had been initial anarthria or mutism. In Case 1 complete anarthria persisted for three months, in Case 2 for some two weeks, and in Case 5 for several days. This last patient, who had a relatively short post-traumatic amnesia (a crushing injury) was able to recollect the early anarthria and to describe his inability to produce articulated sounds. Case 6 was able to describe the process of the return of speech. He remarked quite spontaneously that at the end of eight months he was able to " get out eight or nine words with one breath." In four of the patients the character of the dysarthria was described by observers as being typical of that associated with disease of the cerebellum or its peduncles. Where a more explicit description was given, it appears that the speech was slow, slurred, and scanning. In two patients (Cases 1 and 2), in whom return of speech was watched over several months, it was suggested that the initial mutism was tue to an inability to coordinate breath expulsion with glottis closure and articulation. This phenomenon was also observed in two cases with gunshot wounds of the posterior fossa resulting in brain-stem and cerebellar damage. The recovery went through the stage of forced and unco-ordinated whispering before actual sounds were produced : the condition might be described as an asynergia of speech. When the voice had become strong it was high-pitched, very monotonous, and somewhat explosive; but what chiefly attracted attention was a remarkable lengthening of vowel sounds, whereby a hissing or bleating quality was imparted. It was quite unlike that ordinarily associated with cerebellar disease, for in addition to the gross ataxia there seemed to be some other motor disorder.

Ataxia.-In all the patients except Case 4, pronounced ataxia was a striking feature, and in most it was a gross and disabling symptom. Both sides of the body were severely affected in Case 1 ; in the others one side was chiefly or alone affected. In general it may be said that the ataxic disturbances were of the nature commonly found in severe cerebellar disease. In Cases 1 and 2, oscillations accompanying willed movements were so coarse and of such amplitude that the patient was quite unable to bring his finger to rest on a desired point. In all cases the ataxia was associated with marked inability to perform repetitive movements. When there was difficulty in performing repetitive movements, the facility with which individual movements of the digits could be executed was always impaired, but to a relatively less degree.

Loss of Balance.-Difficulty in maintaining balance and unsteadiness of gait were met with in seven of the nine patients, and in some instances the loss of balance was so extreme that walking was impossible without strong support. None of the patients complained of vertigo.

3 Static Tremor.-In three of our patients a coarse static tremor unassociated with willed movement and persisting for long periods was a very striking 
feature. In Cases 1 and 2 the tremor was confined to one hand, but a nodding tremor of the head was often simultaneously present ; in Case 6 the tremor affected both arm and leg. In no case could the tremor be stopped voluntarily, but it ceased during sleep. Although showing slight differences, the main characteristics of the tremor in these three patients were very similar. The movements, as they affected the digits, were usually of alternate flexion and extension often through a range of twenty or thirty degrees ; but in Case 1 the digit movements were simultaneously associated with a supination-pronation movement of the forearm and hand. In this patient a curious feature was the way in which the tremor would shift from one part of the hand to another, at one time affecting the thumb and index, at another the ring and little fingers. In all three the tremor was coarse, and in Cases 1 and 2 the rate was between two and a half and four oscillations a second, very similar in rate to that seen in paralysis agitans. These rhythmic movements bear a considerable likeness to certain of the tremors studied by Holmes (1904) in which, from the presence of associated signs and, in two cases, from the results of post-mortem examination, a lesion in the tegmentum of the mid-brain was held to be responsible. The tremor was regarded by him as being the result of damage to the red nucleus or superior cerebellar peduncle.

Muscle Tone.-In six patients (Cases 2, 3, 4, 5, 7, 8) the resistance to passive stretching of the muscles was subnormal. In all but one of these (Case 3) the hypotonia was limited to one side, and in all it was predominant on the side showing most ataxia.

Impairment of Function of the Pyramidal Tracts.Except in Case 4, the patients showed at some period changes in the reflexes which suggested a lesion in the pyramidal tracts. The resulting disturbances were usually slight, but they may provide a clue to the localization of the lesion. In six patients (Cases 1, 2, 3, 5, 6, 9) the reflex abnormalities were confined to, or predominated in, the side affected by ataxia and tremor. They were bilateral in one patient (Case 7); and in Case 8, where the "cerebellar" and pyramidal signs were alternate, the pyramidal signs were slight and had entirely cleared up three months after the injury. The tendency of both cerebellar and pyramidal signs to affect the same side of the body was a striking feature and suggests that the lesion lay in the mid-brain and that the cerebellar efferent pathway was damaged above its decussation in the mid-brain. For example, in Case 2 the left arm and leg showed not only loss of tone and gross ataxia, but also Parkinsonian-like tremor and increase of the tendon reflexes. It is possible that some of the alteration in reflex activity may be caused by injury to other descending motor tracts.

Loss of sensation was detected in only one case (Case 6) and affected the same side as showed both cerebellar and pyramidal signs.

Cranial Nerve Involvement.-Disturbance of cranial nerve function was inconspicuous in these cases, except that in all there was some oculo-motor abnormality. In some there was a nuclear type of oculo-motor paresis, while in others the pupils were unequal or their reactions abnormal. Ptosis and lid-retraction were also observed. In only four patients was nystagmus noted, and this was usually slight.

\section{Discussion}

Severe ataxia of the limbs and speech in itself provides a striking post-traumatic syndrome. These cases, however, show more than this, for in addition there was often a Parkinsonian-like tremor, pupillary and oculo-motor disorders, loss of balance, and pyramidal-tract signs. The association of these signs, provided they are due to one lesion, indicates a mid-brain injury. An interesting clinical feature of a unilateral mid-brain lesion at about the level of the lower part of the red nucleus is that, if the superior cerebellar peduncle (after decussation) and the crus are damaged, the expected result would be both cerebellar and pyramidal-tract signs in the contra-lateral limbs. In addition there might be Parkinsonian-like tremor from injury to the red nucleus and substantia nigra, while sign of involvement of the oculo-motor nucleus and medial fillet might easily occur. All these clinical features were well seen in this group of cases, especially where the signs were chiefly unilateral with the cerebellar and pyramidal signs affecting the limbs of one side. The clinical signs alone, therefore, provide strong evidence of mid-brain injury, while the remarkable dilatation of the aqueduct of Sylvius seen in two cases strongly supports this view.

Hæmorrhagic lesions of the mid-brain are wellknown in autopsy studies of rapidly fatal cases. Fig. 4 (kindly lent by Lt.-Colonel Schorstein, R.A.M.C.) illustrates such a lesion from a patient who died about two days after a severe head injury. Holbourn's (1943) convincing studies of the mechanism of brain injury did not include the brain stem. Courville (1945) suggests that mid-brain injury is produced mechanically by bruising against the tentorium, or a rotational strain of the hemispheres pulling on the brain stem. Case No. 5, however, was a crushing injury, in which Holbourn's shearing injury due to rotation could not play a part. In 
this case the skull distortion from compression might have led to some squeezing effect of the brain towards the tentorial opening, with resulting midbrain damage. It might be thought that hyperpyrexia (Freeman and Dumoff 1944) might lead to damage causative of these striking signs, and in Case 1 there was high fever. In hyperpyrexia, however, the motor dysfunction is symmetrical and purely cerebellar. There is also evidence that cerebral-anoxia from respiratory arrest may rarely play an important part in brain damage after head injury, but in anoxia the cerebral hemispheres are first affected.

\section{Summary}

Nine cases of severe closed head injury with severe signs of mid-brain injury are reported. The dominant clinical signs were cerebellar, and included severe dysarthria and disturbance of balance. The cerebellar signs were usually most pronounced on one side, and the limbs of the side showing the maximum ataxia tended also to have increased tendon reflexes, Parkinsonian-like tremor, and, in one case, sensory loss suggesting injury to the medial fillet. These signs are thought to indicate injury to the mid-brain above the decussation of the superior cerebellar peduncles. Additional signs of mid-brain damage were oculo-motor and pupillary disturbances. In at least one case there was early rigidity of all four limbs.

In two cases air encephalography disclosed a marked dilatation of the aqueduct of Sylvius.

We are indebted to Sir Charles P. Symonds, K.B.E., C.B., M.D., F.R.C.P., for his interest and help, and to a number of medical officers at the Military Hospital for Head Injuries, Oxford, for their careful notes. The Director-General, Army Medical Services, has given permission for publication. The Medical Research Council supplied secretarial help.

\section{REFERENCES}

Berner, O. (1930). Virchows Arch., 277, 386.

Courville, C. B. (1945). Proc. Ass. Res. nerv. ment. Dis., 24, 131.

Denny-Brown, D. (1941). Lancet, 1, 371.

Duret, H. (1878). "Traumatismes cérébraux." Paris. - (1919). "Traumatismes cranio-cérébraux." Paris. Freeman, W., and Dumoff, E. (1944). Arch. Neurol. Psychiat. Chicago, 51, 67.

Holbourn, A. H. S. (1943). Lancet, 2, 438.

Holmes, G. (1904). Brain, 27, 327.

Sachs, A. (1930). Rev. Neurol., 2, 422. 